\title{
El primer año de la universidad. Condiciones de trabajo docente, modalidades de admisión y abandono estudiantil desde la perspectiva de los profesores
}

\author{
María-Paula Pierella, Nadia-Soledad Peralta y María-Isabel Pozzo
}

\section{RESUMEN}

El objetivo de este artículo es analizar las perspectivas de profesores de primer año de algunas facultades de la Universidad Nacional de Rosario, Argentina, en relación con las condiciones en que se desarrolla la docencia universitaria. Dentro de estas perspectivas se indagan específicamente las valoraciones sobre el sistema de admisión y los modos en que interpretan el abandono en los primeros años. En el marco de una investigación que contempla una fase cualitativa y una cuantitativa aquí se presentan los resultados obtenidos en la segunda de estas fases. La técnica de recolección de datos implementada fue un cuestionario a docentes de primer año de la universidad mencionada. Se realizó un análisis de correspondencias múltiples, así como análisis bivariados. Los resultados generales indican que la mayoría de los docentes están de acuerdo con el ingreso directo, con instancias de ambientación y acompañamiento, y otorgan centralidad a las problemáticas propias de los ingresantes como causas principales del abandono en primer año. El estudio apunta a destacar la importancia de reconocer al primer año como un ciclo con características específicas.

Palabras clave: abandono escolar, admisión a la universidad, condiciones de trabajo docente, educación universitaria, profesores universitarios, Argentina.

\section{María-Paula Pierella}

pierella@irice-conicet.gov.ar Argentina. Doctora en Ciencias Sociales por la Universidad de Buenos Aires (UBA), Argentina; Magíster en Educación por la Universidad Nacional de Entre Ríos (UNR), Argentina. Investigadora asistente del Consejo Nacional de Investigaciones Científicas y Técnicas (CONICET) en el Instituto Rosario de Investigaciones en Ciencias de la Educación (IRICE), Argentina; docente en la carrera de Ciencias de la Educación, Facultad de Humanidades y Artes, UNR; integrante del Programa de Estudios sobre la Educación Pública (PESUP) en el Instituto de Investigaciones Gino Germani, Facultad de Ciencias Sociales, UBA. Temas de investigación: autoridad pedagógica, vínculos entre estudiantes y profesores en el ámbito de la educación superior, problemática del ingreso a la universidad y la formación del profesorado universitario.

Nadia-Soledad Peralta

nperalta@irice-conicet.gov.ar Argentina. Doctora en Psicología por la Universidad Nacional de San Luis, Argentina; Psicóloga y Profesora en Psicología por la Universidad Nacional de Rosario (UNR), Argentina. Investigadora Asistente del Consejo Nacional de Investigaciones Científicas y Técnicas (CONICET) en el Instituto Rosario de Investigaciones en Ciencias de la Educación (IRICE); docente de la carrera de Psicología de la UNR y miembro de la comisión académica y docente de la Especialización en Psicodiagnóstico de la UNR; directora del Programa Interdisciplinario de Análisis de Datos de la UNR. Temas de investigación: argumentación en estudiantes universitarios, interacción sociocognitiva y análisis de datos.

\section{María-Isabel Pozzo}

pozzo@irice-conicet.gov.ar

Argentina. Doctora en Humanidades y Artes, mención Ciencias de la Educación por la Universidad Nacional de Rosario, Argentina; magíster en Enseñanza de español como lengua extranjera por la Universidad de Barcelona, España; profesora y licenciada en Ciencias de la Educación por la Universidad Nacional de Rosario, Argentina. Investigadora independiente del Consejo Nacional de Investigaciones Científicas y Técnicas (CONICET) en el Instituto Rosario de Investigaciones en Ciencias de la Educación (IRICE); profesora adjunta en la carrera de Ciencias de la Educación, Facultad de Humanidades y Artes, UNR. Temas de investigación: educación intercultural, alfabetización académica y didáctica de la investigación en educación. 
O primeiro ano da universidade. Condições de trabalho docente, modalidades de admissão e abandono estudantil na perspectiva dos professores

\section{RESUMO}

O objetivo deste artigo é analisar as perspectivas de professores de primeiro ano de algumas faculdades da Universidad Nacional de Rosario, Argentina, com relação às condições em que se desenvolvem a docência universitária. Dentro destas perspectivas se indagam especificamente as apreciações sobre o sistema de admissão e os modos em que interpretam o abandono nos primeiros anos. No cenário de uma pesquisa que tem uma fase qualitativa e uma quantitativa, se apresentam os resultados obtidos na segunda destas fases. A técnica de coleta de dados implementada foi um questionário a docentes do primeiro ano da universidade mencionada. Foi realizada uma análise de correspondências múltiplas, assim como análises bivariadas. Os resultados gerais indicam que a maioria dos docentes concordam com a entrada direta, com instancias de ambientação e acompanhamento, e atribuem centralidade às problemáticas próprias dos iniciantes como causas principais do abandono no primeiro ano. O estudo destaca a importância de reconhecer o primeiro ano como um ciclo com características específicas .

Palavras chave: abandono escolar, admissão à universidade, condições de trabalho docente, educação universitária, professores universitários, Argentina.

The first year of college. Working conditions, admission procedures and academic dropout from the teachers' perspective

\section{ABSTRACT}

The main purpose of this article is to analyze the perspectives of first year teachers from some faculties of the National University of Rosario, Argentina, with regard to the conditions in which university teaching is performed. Within these perspectives, the authors specifically investigate the evaluations of the admission system and the ways in which they interpret the academic dropout that takes place during the first years. In the framework of a research that contemplates a qualitative and a quantitative phase, this article presents the results obtained in the second of these phases. The data gathering technique we implemented was a questionnaire to first year teachers of the mentioned university. A multiple correspondence analysis was carried out, as well as bivariate analysis. The general results show that most of the teachers agree with the system of direct admission, setting and accompaniment instances, and that they consider the enrollees' personal problems as the main causes of abandonment during the first year. The study aims to highlight the importance of recognizing the first year as a cycle with specific characteristics.

Key words: school dropout, university admission, teacher working conditions, university education, university teachers, Argentina. 


\section{Introducción}

El primer año de universidad constituye un tramo crítico que, en las últimas décadas, preocupa tanto a investigadores y cientistas sociales como a representantes de políticas públicas e institucionales. El crecimiento de la matrícula universitaria, las altas tasas de discontinuidad en los estudios - que involucran problemáticas como el rezago y el abandono- la heterogeneidad del público estudiantil y la diversificación de las organizaciones de educación superior, constituyen fenómenos globales que plantean desafíos para abordar las especificidades del primer ciclo.

En dicho contexto, se asume que la enseñanza en el primer año es un factor central en el proceso de recepción de los jóvenes a la universidad. Asimismo, se considera a los profesores del primer ciclo como referentes claves en la retención estudiantil. Sin embargo, las condiciones de trabajo de estos actores suelen representar obstáculos materiales para la concreción de políticas de mejora institucional y académica, y para hacer efectiva la democratización universitaria, como principio rector de las últimas décadas.

Partiendo de esta situación problemática, el objetivo de este artículo es analizar las perspectivas de profesores de primer año de algunas facultades de la Universidad Nacional de Rosario (UNR) con relación a las condiciones en que se desarrolla la docencia universitaria. Dentro de estas perspectivas se indagan específicamente las valoraciones que expresan sobre el sistema de admisión y los modos en que interpretan el abandono en los primeros años.

La investigación marco que sustenta este trabajo está compuesta de dos fases: una cualitativa y otra cuantitativa. En esta oportunidad presentaremos los resultados de la segunda fase. En la sección relativa a la metodología utilizada ampliaremos este punto.

\section{El papel de los profesores en los primeros años de la universidad}

A principios del siglo XXI, los procesos de masificación de la universidad pública a nivel global, la brecha cada vez más amplia entre las culturas estudiantiles y las culturas académicas y las problemáticas vinculadas al abandono en el inicio de las carreras, condujeron a pensar al primer año como un tramo crítico que demanda intervenciones en materia de políticas sociales y académicas.

En América Latina, un tema que ha generado creciente interés es en qué medida las universidades cumplen con el objetivo no sólo de garantizar el derecho al acceso a la educación superior, sino también propician la retención y el egreso (Aponte-Hernández, 2008; Chiroleu, 2009; Ezcurra, 2011; García de Fanelli, 2015).

En lo referente al grado de avance de la cobertura, Argentina presenta una alta tasa de matriculación en el nivel superior, semejante a la que muestran varios países europeos (García de Fanelli, 2015). En 2017, la Tasa Bruta de Escolarización Superior (TBES) es $57.8 \%$. Cerca del $80 \%$ de los estudiantes de grado asisten a universidades públicas. Por su parte la tasa de egreso computada por la Encuesta Permanente de Hogares realizada en 2010 es del 17\% (García de Fanelli, 2015). Cabe, sin embargo, tener en cuenta datos sobre la evolución de la cantidad de nuevos inscritos, estudiantes y egresados. Entre 2007 y 2016 el número de estudiantes aumentó el 26.3\%; los nuevos inscritos $35 \%$ y la cantidad de egresados $44 \%$ (Ministerio de Educación de la Nación Argentina, 2017).

En general, las investigaciones de las últimas décadas destacan la necesidad de superar enfoques centrados en los estudiantes como sujetos responsables de sus propios fracasos, para atender a los condicionantes políticos e institucionales. Un referente en esta línea es el norteamericano Vincent Tinto (1993), cuyos estudios desde finales de la década de 1980, abordan el problema del abandono desde este enfoque. Este autor cuestiona las explicaciones del "fracaso" estudiantil centradas en enfatizar los factores psicológicos de los propios sujetos. Desde estas perspectivas, eran los estudiantes los que no alcanzaban 
las competencias requeridas por la universidad. De ahí, el uso peyorativo del término dropout, o claudicar. De modo contrario, Tinto sostiene que el abandono de los estudios responde tanto a problemáticas de los estudiantes como de la institución, a la naturaleza del ambiente institucional, al contexto social y académico de la universidad, y a la manera en que el cuerpo docente, las autoridades, los profesores y los estudiantes interactúan unos con otros sobre cuestiones de carácter académico y social (Tinto, 1993).

En Europa, a partir del reconocimiento de que la transición entre la escuela media y la universidad influye en la permanencia de los estudiantes, se consolidaron líneas de indagación centradas en la experiencia del primer año de universidad (First year experience) (entre otros, Yorke y Longden, 2007; Johnston, 2013). Asimismo, se avanzó en la construcción de modelos de acogida estudiantil (Michavila Pitarch, 2015). Los desarrollos de Coulon (2008) han focalizado en la indagación de los procesos de afiliación institucional e intelectual necesarios para acceder a la condición de estudiante. En esa línea, dicho autor pregona por el desarrollo de una "pedagogía de la afiliación", que involucra indefectiblemente a los profesores de primer año.

Más recientemente, en América Latina se observa un crecimiento de los estudios sobre la vida estudiantil (entre otros, De Garay, 2001; Krotsch, 2002; Ortega, 2008; Carli, 2012; Guzmán, 2013; Blanco, 2014; Pierella, 2014; Mancovsky, 2015). Asimismo, se advierte sobre la necesidad de encarar investigaciones que consideren la incidencia de factores institucionales, académicos y pedagógicos en el carácter crítico de dicho tramo inicial (entre otros, Ezcurra, 2011; Figuera y Álvarez, 2014; Gluz, 2011).

En Argentina, la problemática de las altas tasas de abandono en muchas de las universidades - que es un tema de alcance global - lleva a diferentes autores a afirmar que el sistema universitario, pese a su carácter abierto, generaría mecanismos de selectividad implícita (véase entre otros, Chiroleu, 1999; Sigal, 1993) o fenómenos de inclusión excluyente (Ezcurra, 2011) que afectan en particular a jóvenes de sectores sociales que no cuentan con las disposiciones requeridas por la universidad. ${ }^{1}$ Cabe señalar que, si bien el acceso a la educación superior se encuentra diferenciado según el nivel de ingresos de las familias de los estudiantes, en la última década tiene lugar un incremento de la representación de los sectores populares. Mientras que en 2004, un $10.76 \%$ de los casos analizados de jóvenes pertenecientes al primer quintil se encuentra cursando alguna carrera de educación superior, en 2008 la representación de estos sectores se incrementa, alcanzando un $13.11 \%$ de asistencia en 2008 y un $15.62 \%$ en 2012 , lo que representa un avance en términos de oportunidades de acceso para los grupos de menores ingresos del país (Suasnábar y Rovelli, 2016). Con relación a la tasa de egreso, se observa que durante el periodo 2004-2012 aumenta del 5 al 6.3\% para los jóvenes de los primeros quintiles. A su vez, la representación de egresados del segundo quintil crece del 9.8 al 12.2\%. (Suasnábar y Rovelli, 2016).

En este contexto, se indica que las políticas más eficaces son las de segunda y tercera generación, en tanto desplazan el foco de atención desde los sujetos

\footnotetext{
${ }^{1}$ Durante los primeros gobiernos peronistas (1946-1955) se implementa la gratuidad de los estudios universitarios (1949) y el ingreso irrestricto (1953), sin exámenes y sin cupos por carrera o universidad. En los periodos dictatoriales se vuelve a incorporar el examen de ingreso, eliminándose en la mayoría de las universidades con el retorno a la democracia en 1983. En la década de 1990, en un contexto claramente neoliberal, la Ley de Educación Superior 24521 les otorga autonomía a las universidades —y en el caso de aquellas instituciones con más de 50000 estudiantes a las facultades - para establecer el régimen de admisión, permanencia y promoción de los estudiantes. La reactivación del debate sobre el ingreso durante los últimos años se vincula con la situación de heterogeneidad de los sistemas de admisión habilitados por la LES y en particular con la sanción en 2015, al final del segundo gobierno de Cristina F. de Kirchner, de la Ley 27204 de Implementación efectiva de la responsabilidad del Estado en el Nivel de Educación Superior. Se trata de una modificatoria a la LES, que le atribuye al Estado la responsabilidad indelegable y principal respecto a la educación superior, y considera a la educación y al conocimiento como bienes públicos y derechos humanos. En este sentido, entre otras modificaciones, se incorporan artículos que instalan a la gratuidad y al ingreso irrestricto como principios indiscutibles.
} 
hacia los mecanismos institucionales y las condiciones de enseñanza (IEG-CONADU, 2014), de tal manera que se tiende a revisar los supuestos de una institución que en muchas de sus prácticas continúa siendo elitista. Gradualmente, el ingreso de sectores sociales anteriormente excluidos de la educación superior, ha implicado una suerte de ruptura entre las figuras de los estudiantes "deseados" y los estudiantes reales, evidenciándose una mayor preocupación por pensar de modo más articulado el conocimiento, su enseñanza y los sujetos destinatarios de la misma (Ezcurra, 2011; Feldman, 2015). En este sentido, resulta imperioso revisar el primer año desde una perspectiva inclusiva que apunte a la afirmación de derechos. Gluz (2011) encuentra que ciertos dispositivos institucionales contribuyen en la pervivencia de una desigualdad cultural socialmente condicionada. Por su parte, Ezcurra (2011), basándose en trabajos de autores norteamericanos, afirma que la enseñanza en sentido amplio y en especial las experiencias académicas cotidianas, tienen un papel causal concluyente en la permanencia y en el desempeño académico de los estudiantes. Asimismo, Carli (2014) plantea que la enseñanza universitaria se ve desafiada a trabajar política y académicamente con las diferencias y desigualdades de la población estudiantil.

En ese marco, los profesores en general y los de primer año en particular, constituirían actores centrales para cualquier esfuerzo de mejora institucional (véase, entre otros, Silva Laya, 2011; Johnston, 2013; Socolovsky, 2014; Rinesi, 2015; Pierella, 2018). Sobre ellos recaería la compleja tarea de no sólo recibir a los ingresantes sino retenerlos, de modo tal de tender hacia la efectivización de la educación superior como un derecho humano y social. La Declaración Final de la Conferencia Regional de Educación Superior celebrada en Cartagena de Indias en 2008, es clara al respecto. Allí se sostiene que la educación superior es un derecho humano y un bien público y social. Resulta un deber de los Estados garantizar este derecho y definir, junto a las sociedades nacionales y las comunidades académicas, los principios básicos en los cuales se fundamenta la formación de los ciudadanos y ciudadanas, velando por que ella sea pertinente y de calidad (IESALC-UNESCO, 2008). Desde esta perspectiva, masividad y calidad no serían variables antagónicas, como se las analiza desde sectores opuestos al ingreso irrestricto, sino aspectos interdependientes.

Ahora bien, los docentes de primer año que, como se dijo antes, resultan claves al momento de pensar políticas orientadas a mejorar las condiciones de acceso, permanencia y egreso, ejercen su tarea de enseñanza en condiciones que no suelen ser las más favorables. Las transformaciones sociales que desde los ochenta afectaron la estructura y dinámica de los sistemas universitarios a nivel mundial - principalmente los procesos de mercantilización e internacionalización del conocimiento en función del paradigma empresarial propio del neoliberalismo- son el marco general en el que se inscribe el ejercicio actual de la docencia universitaria (Juarros et al., 2016). Frente a la masificación del nivel, se implementaron dispositivos y estrategias de racionalización del financiamiento del trabajo docente desde parámetros que priorizan la evaluación del desempeño individual desde una lógica centrada en la productividad (Juarros et al., 2016).

En el caso argentino, las dificultades de la profesión académica se han asociado a la rigidez de la organización de cátedras, la mayor ponderación de la investigación en detrimento de otras actividades como la docencia o la extensión-, la falta de reconocimiento de tareas de gestión y gobierno (Carli, 2016; García de Fanelli y Moguillansky, 2009), la menor dedicación de los docentes y la inestabilidad de sus cargos (Fernández Lamarra y Pérez Centeno, 2011) .

Si bien el aumento de cargos docentes en los últimos años ha sido importante, manteniendo una relación de 1 a 10 con el número de estudiantes, es preciso advertir que esta proporción no se encuentra distribuida de modo homogéneo, teniendo 
el conjunto del sistema más de un 60\% de cargos simples y sólo alrededor de un $12 \%$ de dedicaciones exclusivas (SPU, 2017). ${ }^{2}$

El problema de las escasas dedicaciones exclusivas de los cargos docentes es un aspecto dentro de las condiciones de trabajo estructurales, que se suma a problemas de infraestructura, falta de presupuesto para la adquisición de material didáctico, entre otros. Asimismo, cabe mencionar cuestiones de índole organizacional, o de política académica, como la dificultad para estructurar al primer ciclo como una unidad con identidad propia, o la necesidad de profundizar los programas de formación docente. En relación con este último punto es posible sugerir que la enseñanza en los primeros años de las carreras requiere de una capacitación específica y condiciones particulares para su ejercicio (IEC-CONADU, 2014). Si bien en los últimos años tuvo lugar un crecimiento tanto de la oferta como de la demanda de posgrados, junto a decisiones políticas fundamentales en dicha área, ${ }^{3}$ en general los profesores de las universidades de Argentina no tienen una formación pedagógica.

En términos generales, la situación descrita atraviesa a los docentes universitarios de todos los ciclos. Sin embargo, las limitaciones estructurales adquieren una dimensión mayor en los primeros años, al encontrarse dichos actores frente al desafio de garantizar condiciones de enseñanza favorables que propicien la retención de los estudiantes.

\section{Método}

Esta investigación fue realizada en la Universidad Nacional de Rosario (UNR), en la ciudad homónima localizada en la provincia de Santa Fe, Argentina. La ciudad de Rosario se ubica en tercer lugar en términos poblacionales del país, luego de Buenos Aires y Córdoba. En la región Centro-Este del país, que incluye a las provincias de Santa Fe y Entre Ríos, se matricula el $11 \%$ de los estudiantes de grado y se registra el 15\% de los egresados de Argentina. Con relación a este dato, la región posee la mayor importancia en cuanto a la cantidad de egresados por cada 1000 habitantes, que asciende a 3.8. Asimismo, respecto del indicador de la tasa de graduación (egresados por cada 1000 estudiantes), se observan los mejores valores a nivel nacional, con una tasa de 85 egresados por cada 1000 estudiantes (Fachelli y López Roldán, 2017).

La UNR, fundada en 1968, es una de las universidades más grandes del país, con 81751 estudiantes y 2153 egresados, según información disponible en el Boletín Estadístico de 2018. Esta institución alberga 12 facultades y tres institutos de enseñanza media. Asimismo, la Universidad cuenta con 7861 cargos y 6350 docentes.

Desde un punto de vista metodológico, la investigación se inicia con un análisis cualitativo, siguiendo el objetivo de indagar los sentidos construidos por los profesores de primer año sobre la enseñanza en dicho ciclo. Luego, en un segundo momento, se propusieron hipótesis cuantitativas, empleando una definición de variables realizada a partir de los resultados de la primera etapa cualitativa (Gallart, 1992). De este modo, se procuró enriquecer los análisis cualitativos basados en entrevistas narrativas a docentes de primer año de tres facultades de la UNR (Ciencias Exactas, Ingeniería y Agrimensura; Ciencia Política y Relaciones Internacionales, y Ciencias Económicas y Estadística) con un análisis cuantitativo de cuestionarios administrados en línea. En este artículo presentamos los resultados de esta segunda fase.

En este segundo momento, entonces, diseñamos un cuestionario para que se autoadministrara por internet, considerando la posibilidad que brinda de

\footnotetext{
${ }^{2}$ Según el Decreto 1246: Convenio Colectivo para los docentes de las instituciones universitarias nacionales, de julio de 2015, las dedicaciones docentes son: Exclusiva: 40 horas semanales; Semiexclusiva: 20 horas semanales y Simple: 10 horas semanales (Artículo 9). ${ }^{3}$ Cabe tener en cuenta aquí la implementación en 2007 del Programa de Capacitación Gratuita para Docentes de Universidades Nacionales, implementado desde la Secretaría de Políticas Universitarias y en acuerdo con las asociaciones gremiales de docentes universitarios.
} 
acceder a un amplio número de personas con gran rapidez, la facilidad para cuantificar y analizar los datos, los escasos requerimientos de personal, la posibilidad de mantener el anonimato de los encuestados y eliminar ciertos sesgos que introducen los encuestadores; entre otras ventajas (Canales et al., 1994; Díaz de Rada, 2012; Hernández-Sampieri et al., 2008). No obstante, cabe tener en cuenta también las limitaciones de esta técnica; algunas de las desventajas señaladas por Coomber (1997) guardan relación con la escasa flexibilidad y dificultad para profundizar en la información obtenida; riesgo de que no llegue a los destinatarios esperados o que no se obtenga respuesta; imposibilidad de aclarar dudas sobre las preguntas; dificultad para obtener una tasa alta de cuestionarios completos. Específicamente, cuando se trata de cuestionarios en línea, se encuentran los errores de cobertura, escaso control sobre los encuestados y, por tanto, de las muestras obtenidas. Un problema adicional del medio digital refiere a la sospecha de un mensaje con virus, ante el cual el destinatario ni siquiera atine a responder (Pozzo, Borgobello y Pierella, 2018).

El cuestionario aludido fue entonces ampliamente distribuido por correo electrónico, en soporte digital disponible online, aportando datos sobre los objetivos de la investigación y el tratamiento anónimo de los datos en las publicaciones derivadas del estudio. Éste se compuso de 23 preguntas cerradas y una última pregunta abierta destinada a realizar comentarios o aclaraciones sobre las respuestas anteriores, o alguna reflexión sobre las problemáticas, desafíos, cuestiones pendientes, etcétera, que encuentre en su trabajo como docente de primer año. Las primeras preguntas apuntaban a revelar datos sociodemográficos y de hábitos de los docentes como el género, la franja etaria, la antigüedad y tipo de cargo, dedicación, titulaciones, inserción o no en el sistema científico, cantidad estimada de estudiantes a cargo, carreras o cursos de formación docente realizados, modalidad de las clases dictadas, soportes y materiales utilizados.
El resto de las preguntas intentaba, por un lado, obtener información sobre sus perspectivas en relación con las condiciones de trabajo como docentes en el primer año de la universidad. Así, se indagó el grado de acuerdo con el modo en que desarrollan su trabajo, teniendo en cuenta aspectos como relación tiempo y tipo de tarea-salario, condiciones edilicias, distribución del trabajo en las cátedras, equipamiento y recursos disponibles. Por otro lado, se revelaron las posiciones en relación con las modalidades de admisión al sistema, las causas atribuidas al abandono, el grado de acuerdo con la necesidad de formación pedagógica de los docentes universitarios en general y de formación específica para enseñar en primer año, en particular.

Para analizar estas últimas respuestas tuvimos en cuenta algunos elementos del análisis de percepciones. El concepto de percepciones aparece fuertemente anclado a la perspectiva gestáltica, entendido como un proceso de formación de representaciones mentales, cuya función es realizar abstracciones a través de las cualidades que definen lo esencial de la realidad externa (Oviedo, 2004: 96). Sin embargo, su uso trasciende dicha postura psicológica y es adoptado extensivamente, desde fines de la década de los sesenta del siglo pasado, en estudios que pretenden superar el mero análisis de prácticas visibles de profesores en el aula para entenderlas como productos complejos derivados de una trama de valores y creencias fundados en concepciones construidas a lo largo de la vida.

\section{Participantes}

La muestra estuvo constituida por 59 sujetos, todos ellos docentes de primer año de la UNR que se desempeñan en facultades correspondientes a distintas áreas del conocimiento (exactas, políticas y económicas y empresariales). Del total de docentes que respondieron el cuestionario, el $61 \%$ es de sexo femenino y el 39\% masculino. El 33.9\% tiene más de 50 años, el $32.2 \%$ entre 30 y 39 , el $23.7 \%$ entre 40 y 49 y el $10.2 \%$ restante entre 20 y 29 años. 
El 11.9\% tiene el cargo de ayudante de segunda, $20.3 \%$ ayudante de primera, el $28.8 \%$ jefe de trabajos prácticos, el $27.1 \%$ adjunto y el $27.9 \%$ titular o asociado. ${ }^{4}$ El 50.8\% tiene una dedicación simple a la docencia, mientras que el $25.4 \%$ tiene dedicación semiexclusiva y el 23.7\% dedicación exclusiva. El $67.8 \%$ tienen su cargo por concurso interno y el $32.2 \%$ por concurso oficial.

El 39\% tiene entre 0 y 10 años de antigüedad y el $61 \%$ restante más de 10 años de antigüedad. El $62.8 \%$ de la muestra tiene algún tipo de formación docente de grado o posgrado y el $78 \%$ de la muestra está realizando o ha finalizado un posgrado.

\section{Resultados}

En primer lugar, con un objetivo exploratorio, se realizó un análisis de correspondencias múltiples para observar simultáneamente las relaciones entre todas las variables nominales estudiadas agrupadas en tres dimensiones: datos sociodemográficos y hábitos de los docentes; perspectivas en relación con las condiciones de trabajo docente, posiciones con respecto a las modalidades de admisión al sistema y causas atribuidas al abandono de los estudiantes.

En segundo lugar, se realizaron análisis bivariados de cada pregunta del cuestionario, con el fin de analizar a detalle las respuestas a cada uno de estos ítems.

\section{Análisis Multivariado (análisis de correspondencias múltiples)}

El análisis multivariado se basa en los estudios propuestos por la escuela francesa de Benzécri y Morineau, que vincula técnicas de análisis factorial y de clasificación. Su valor recae fundamentalmente en la representación gráfica de los datos, que posibilita un acercamiento a la estructura de los mismos, bajo una lógica más inductiva que deductiva y revalorizando el rol de los individuos (Moscoloni, 2005). En función de dichas características, este tipo de enfoque fue adoptado en el presente trabajo. En la figura 1 se puede apreciar la combinación articulada de las diversas dimensiones.

\section{Figura 1. Representación gráfica de las variables nominales activas en el plano factorial}

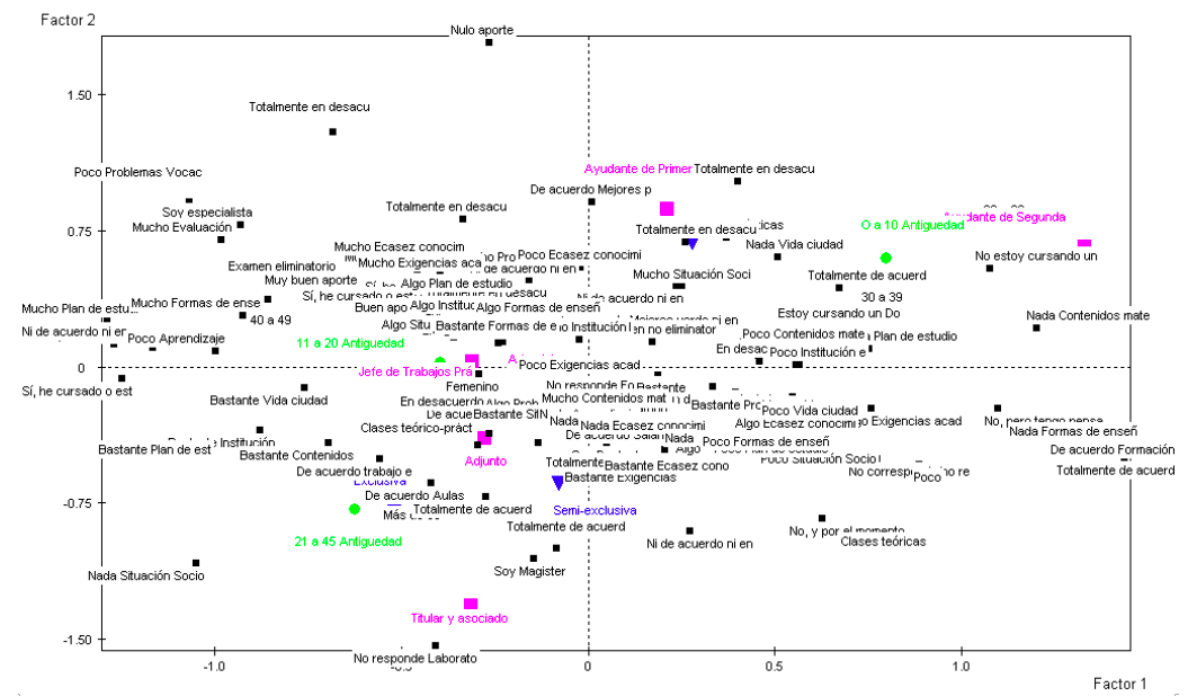

Fuente: elaboración propia.

\footnotetext{
${ }^{4}$ En las universidades de Argentina, en general, "la jerarquía docente se conforma de la siguiente manera: Profesor Titular (Jefe de Cátedra), Profesores Asociados y Adjuntos, Jefes de Trabajos Prácticos (JTP), Auxiliares de Primera (A1) y Auxiliares de Segunda (A2). Los A1 son graduados universitarios (por lo general recientes) y los A2 son aún estudiantes de la carrera que han aprobado la materia en la que se encuentran participando" (Borgobello y Peralta, 2011: 49).
} 
Como puede observarse en la figura 1 , en el factor 1, o eje horizontal, prevalece la edad y la antigüedad de los docentes. Hacia la derecha se concentran las variables vinculadas con los más jóvenes (20 a 29 y 30 a 39 años) que dictan clases prácticas, con cargos simples, fundamentalmente ayudantes de segunda y de sexo masculino, quienes consideran que el plan de estudios, los contenidos de las asignaturas, las formas de enseñanza, la vida institucional y la vida en la ciudad poco inciden en el abandono de la carrera de los estudiantes de primer año. Están en desacuerdo con las condiciones laborales, principalmente con las condiciones edilicias, y consideran que los docentes de primer año deberían tener una formación específica para desempeñarse en ese cargo.

Hacia la izquierda se ubican los docentes con mayor antigüedad (21 a 45 años) y edad (de 40 años en adelante) que dictan clases teórico-prácticas, con cargos de dedicación exclusiva y de sexo femenino. Consideran que los estudiantes abandonan porque tienen muchas dificultades de aprendizaje, para adaptarse a las exigencias académicas y para aprobar las evaluaciones, y piensan que la forma de ingreso debería ser por examen eliminatorio.

En el eje vertical, hacia abajo se encuentran los titulares y asociados con más de 50 años de edad, con dedicaciones exclusivas a la docencia, formación de posgrado (maestrías y doctorados). En general están de acuerdo con sus condiciones laborales y consideran que los estudiantes tienen bastantes dificultades para adaptarse a las exigencias académicas, déficit en los aprendizajes y escasez de conocimientos previos.
En la parte superior se ubican los ayudantes de primera, con escasa antigüedad docente (de 0 a 10 años), quienes dictan clases prácticas con dedicaciones simples. Están en desacuerdo con las condiciones laborales y consideran que los estudiantes tienen muchas dificultades en el plano de los aprendizajes, en las evaluaciones y una escasez de conocimientos previos.

Por último, se realizó el análisis de clasificación que enriqueció los datos obtenidos anteriormente vinculados a las variables. Se definieron tres clases, cada una de ellas se distingue de la otra por el predominio de un grupo de variables, lo que no significa que no estén presentes en la otra clase aunque con menor intensidad. En la tabla 1 se muestran las variables que realizan aportes significativos a la definición de cada clase.

Como puede observarse, los clusters se caracterizan fundamentalmente por la edad de los docentes, constituyéndose un cluster con los más jóvenes con cargos de dedicación simple y poca antigüedad; el segundo cluster, caracterizado por los sujetos de entre 40 a 49 años de edad con una opinión centrada en que las principales causas de abandono de los estudiantes de primer año estarían vinculadas a características propias (poco conocimiento previo, dificultades para las evaluaciones y cumplimentar las exigencia académicas básicas, por ejemplo la lectura y escritura). Finalmente, el tercer cluster, caracterizado fundamentalmente por los docentes con mayor antigüedad que consideran que las mayores dificultades se encuentran en los aprendizajes y exigencias académicas.

Para finalizar, se proyectaron los casos en el espacio factorial diferenciándose su pertenencia a cada clase. 
Tabla 1. Descripción de las variables continuas que aportaron significativamente a la definición de los clusters

\begin{tabular}{|c|c|c|c|c|c|}
\hline Clase & $N(\%)$ & Modalidad de la variable de mayor aporte & $\begin{array}{c}\text { \% de la } \\
\text { categoría } \\
\text { en el cluster }\end{array}$ & Valor test & Probabilidad \\
\hline \multirow{6}{*}{ Clase 1} & \multirow{6}{*}{35.59} & 0 a 10 años de antigüedad & 85.71 & 5.34 & 0.000 \\
\hline & & Dedicación simple & 90.48 & 4.44 & 0.000 \\
\hline & & No cursó posgrado & 52.38 & 22.03 & 0.000 \\
\hline & & Clases prácticas & 71.43 & 3.54 & 0.000 \\
\hline & & Ayudantes de segunda & 33.33 & 3.40 & 0.000 \\
\hline & & de 30 a 39 años & 61.90 & 3.32 & 0.000 \\
\hline \multirow{7}{*}{ Clase 2} & \multirow{7}{*}{25.42} & Mucho-dificultades para aprobar evaluaciones & 80.00 & 5.40 & 0.000 \\
\hline & & Cursando una maestría & 46.67 & 4.12 & 0.000 \\
\hline & & De 40 a 49 años & 66.67 & 4.00 & 0.000 \\
\hline & & Mucho-dificultades en el aprendizaje & 80.00 & 3.64 & 0.000 \\
\hline & & Mucho-Exigencias académicas & 80.00 & 2.97 & 0.001 \\
\hline & & Mucho-Escasez de conocimientos & 66.67 & 2.74 & 0.003 \\
\hline & & Examen eliminatorio & 33.33 & 2.37 & 0.009 \\
\hline \multirow{5}{*}{ Clase 3} & \multirow{5}{*}{38.99} & Bastante-dificultades en el aprendizaje & 73.91 & 3.46 & 0.000 \\
\hline & & Mucho- Exigencias académicas & 56.52 & 2.90 & 0.002 \\
\hline & & Más de 50 años & 56.52 & 2.65 & 0.004 \\
\hline & & Doctorado finalizado & 52.17 & 2.33 & 0.010 \\
\hline & & Clases teórico-prácticas & 78.26 & 2.33 & 0.010 \\
\hline
\end{tabular}

Fuente: elaboración propia.

Figura 2. Representación gráfica de las clases en el espacio factorial

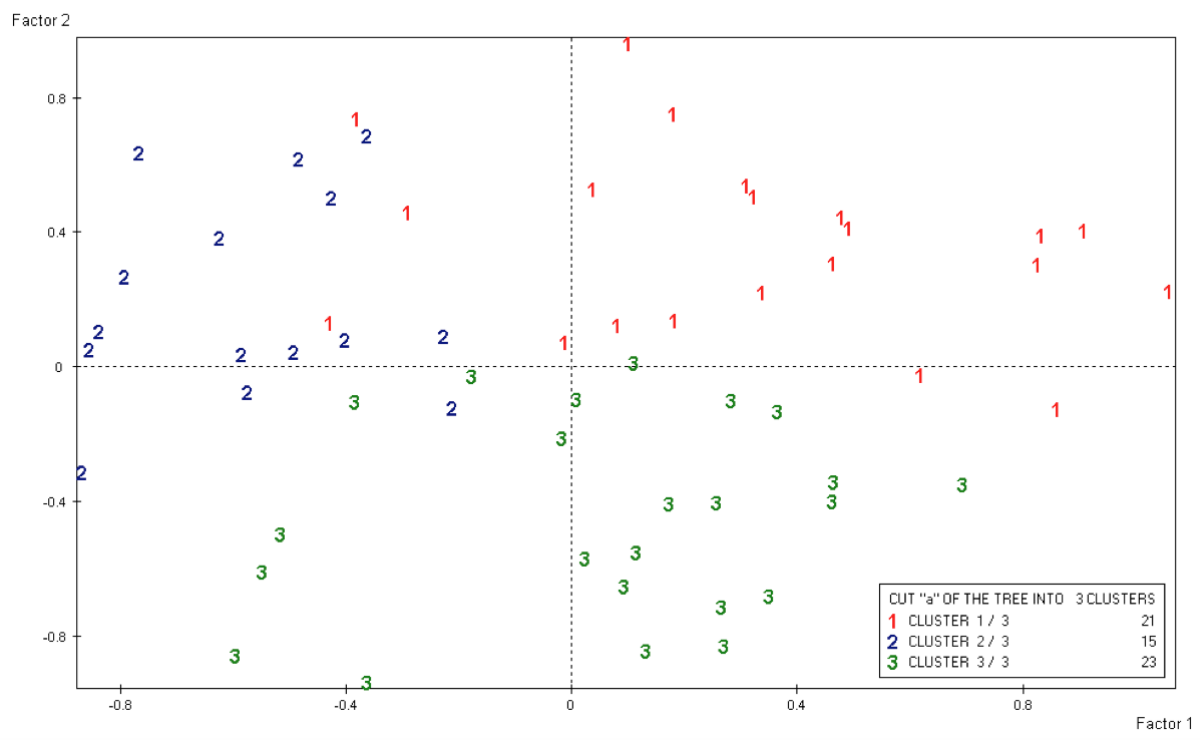




\section{Análisis bivariado}

¿Qué opinan los docentes sobre las

\section{condiciones laborales?}

En relación con las condiciones laborales, el 30.5\% está en desacuerdo con su salario y el $18.6 \%$ totalmente de acuerdo.
El 40.7\% considera que las aulas en donde dan clases no están en buenas condiciones para el trabajo docente. Un 28.8\% piensa que los laboratorios están bien equipados y presentan condiciones seguras. Y la mayoría considera que el trabajo no se reparte de manera equitativa en la cátedra en la que participa.

Tabla 2. Opinión de los docentes sobre las condiciones laborales

\begin{tabular}{|c|c|c|c|c|}
\cline { 2 - 5 } \multicolumn{1}{c|}{} & \multicolumn{4}{c|}{ Condiciones laborales } \\
\hline & $\begin{array}{c}\text { El salario que recibo es } \\
\text { adecuado con el trabajo } \\
\text { que realizo }\end{array}$ & $\begin{array}{c}\text { Las aulas presentan } \\
\text { buenas condiciones para el } \\
\text { trabajo con los estudiantes }\end{array}$ & $\begin{array}{c}\text { Los laboratorios están bien } \\
\text { equipados y presentan } \\
\text { condiciones seguras }\end{array}$ & $\begin{array}{c}\text { Dentro de mi cátedra } \\
\text { el trabajo se reparte de } \\
\text { modo equitativo }\end{array}$ \\
\hline Totalmente de acuerdo & $11(18.6 \%)$ & 0 & 0 & $2(3.4 \%)$ \\
\hline De acuerdo & $15(25.4 \%)$ & $14(23.7 \%)$ & $17(28.8 \%)$ & $15(25.4 \%)$ \\
\hline $\begin{array}{c}\text { Ni de acuerdo ni en } \\
\text { desacuerdo }\end{array}$ & $9(15.3 \%)$ & $5(8.5 \%)$ & $13(22 \%)$ & $18(30.5 \%)$ \\
\hline $\begin{array}{c}\text { En desacuerdo } \\
\text { Totalmente en } \\
\text { desacuerdo }\end{array}$ & $18(30.5 \%)$ & $24(40.7 \%)$ & $16(27.1 \%)$ & $18(30.5 \%)$ \\
\hline No responde & $6(10.2 \%)$ & $16(27.1 \%)$ & $8(13.6 \%)$ & $2(3.4 \%)$ \\
\hline
\end{tabular}

Fuente: elaboración propia.

Con relación a la capacitación —uno de los elementos cualitativos de las condiciones de trabajo-, el 18.6\% de los docentes no realizó ninguna instancia de formación docente ni tiene pensado hacerlo; otro $18.6 \%$ no se ha formado pero sí tiene pensado hacerlo en el futuro; una gran parte $(47.5 \%)$ ha cursado o está cursando el profesorado y el $15.3 \%$ restante ha cursado o está cursando una especialización o maestría vinculada con la formación docente. Considerando en su conjunto a los docentes que han realizado alguna instancia de formación, la mayoría $(67.5 \%)$ consideró como moderado o bueno el aporte realizado para su formación como docente universitario.

\section{¿Qué sistema de admisión prefieren los docentes?}

El 58\% de los docentes considera que el ingreso directo con instancia de ambientación es el más adecuado; $18.6 \%$ prefieren el examen eliminatorio sin cupo; $18.6 \%$ optan por el examen no eliminatorio y un $11.9 \%$, el examen eliminatorio con cupo (ver gráfico 1). 


\section{Gráfico 1. Opinión de los docentes con respecto a los sistemas de admisión}

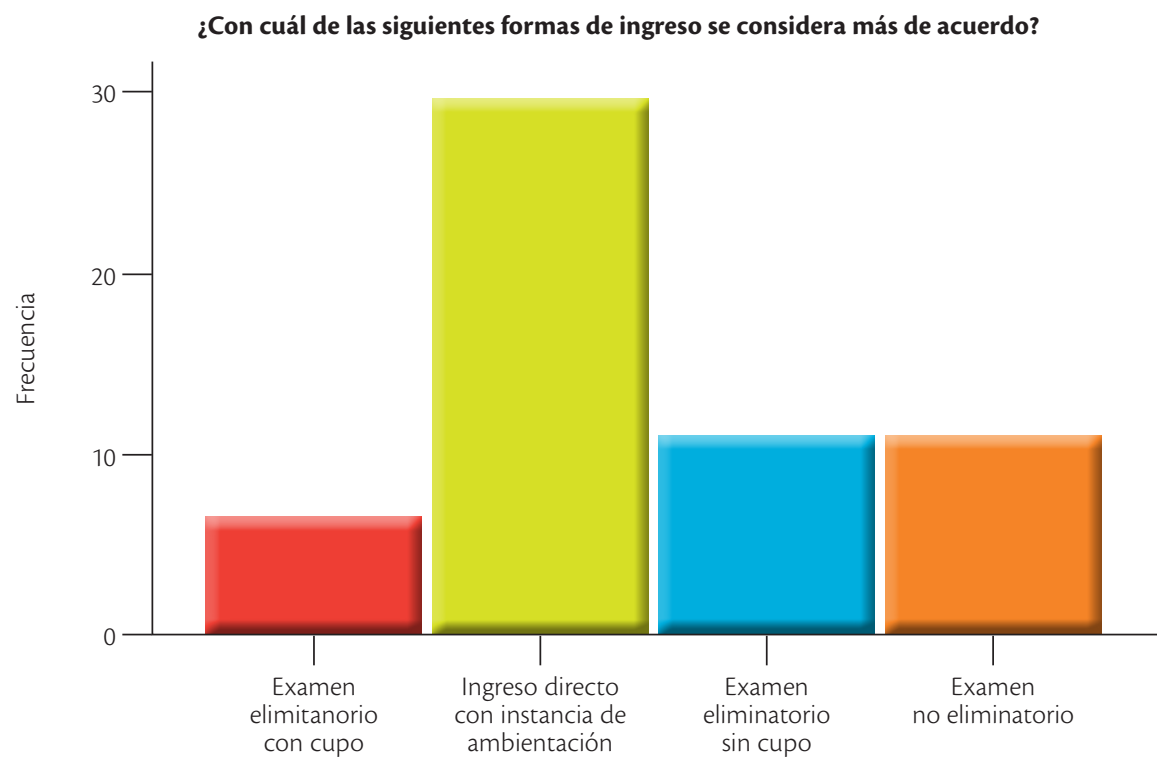

\section{¿Cuáles son las causas que explican el abandono en primer año?}

Con respecto a las dificultades vinculadas con la institución o específicamente la asignatura, los docentes consideran que es poca la influencia de las dificultades de los estudiantes propias de ingresar a una nueva institución con reglas novedosas (40.7\%); el $33.9 \%$ considera que es poca la influencia de la organización del plan de estudios entre los motivos de abandono, así como los contenidos de las materias, y el 30.5\% considera que la forma de enseñanza influye bastante en el abandono de los estudiantes. Como puede observarse en la tabla 3, las dificultades institucionales y de las asignaturas no son consideradas fundamentales a la hora de pensar posibles causas del abandono.

Tabla 3. Dificultades vinculadas con la institución y las asignaturas como causas de abandono

\begin{tabular}{|c|c|c|c|c|}
\hline & \multicolumn{3}{|c|}{ Dificultades vinculadas con la Institución y la asignatura } \\
\hline & $\begin{array}{c}\text { Ingreso a una institución } \\
\text { con nuevas normativas }\end{array}$ & $\begin{array}{c}\text { Organización del plan de } \\
\text { estudios }\end{array}$ & Contenidos de las materias \\
\hline Fucho & $1(1.7 \%)$ & $2(3.4 \%)$ & 0 & $14(23.7 \%)$ \\
\hline Bastante & $14(23.7 \%)$ & $6(10.2 \%)$ & $21(35.6 \%)$ \\
\hline Algo & $14(23.7 \%)$ & $22(37.3 \%)$ & $18(3.5 \%)$ \\
\hline Poco & $24(40.7 \%)$ & $20(33.9 \%)$ & $21(35.6 \%)$ \\
\hline Nada & $6(10.2 \%)$ & $9(15.3 \%)$ & $17(28.8 \%)$ \\
\hline
\end{tabular}


Tabla 4. Dificultades vinculadas con el estudiante como causas de abandono

\begin{tabular}{|c|c|c|c|c|c|}
\cline { 2 - 6 } & \multicolumn{5}{|c|}{ Dificultades vinculadas con el estudiante } \\
\cline { 2 - 6 } & $\begin{array}{c}\text { Aprobación de } \\
\text { evaluaciones }\end{array}$ & $\begin{array}{c}\text { Adaptación a } \\
\text { exigencias académicas }\end{array}$ & $\begin{array}{c}\text { Escasez } y \\
\text { conocimientos previos }\end{array}$ & $\begin{array}{c}\text { Problemas } \\
\text { vocacionales }\end{array}$ & $\begin{array}{c}\text { Aspectos del } \\
\text { aprendizaje }\end{array}$ \\
\hline Mucho & $14(23.7 \%)$ & $26(44.1 \%)$ & $20(33.9 \%)$ & $10(16.9 \%)$ & $22(37.3 \%)$ \\
\hline Bastante & $25(42.4 \%)$ & $19(32.2 \%)$ & $19(32.2 \%)$ & $28(47.5 \%)$ & $26(44.1 \%)$ \\
\hline Algo & $14(23.7 \%)$ & $12(20.3 \%)$ & $15(25.4 \%)$ & $16(27.1 \%)$ & $10(16.9 \%)$ \\
\hline Poco & $6(10.2 \%)$ & $2(3.4 \%)$ & $5(8.5 \%)$ & $5(8.5 \%)$ & $1(1.7 \%)$ \\
\hline Nada & 0 & 0 & 0 & 0 & 0 \\
\hline
\end{tabular}

Fuente: elaboración propia.

En relación con las dificultades vinculadas con el estudiante, los docentes consideran que es notable la influencia de la desaprobación recurrente de las evaluaciones en el abandono (el 42.4\% considera que es bastante), junto con la adaptación a las exigencias académicas (44.1\% mucho) y la escasez de conocimientos previos (33.9\% mucho). El $47.5 \%$ piensa que es bastante la influencia de problemas vocacionales a la hora de dejar los estudios mientras que el $44.1 \%$ califica de esa manera al rol de las dificultades en diferentes aspectos del aprendizaje.

Finalmente, el 33.9\% sostiene que la situación económica familiar sería un factor que influye en el abandono mientras que la mayoría piensa que las dificultades para adaptarse a la vida en la ciudad tendría poca influencia (ver tabla 5).

Tabla 5. Dificultades vinculadas a condiciones externas

\begin{tabular}{|c|c|c|}
\cline { 2 - 3 } \multicolumn{1}{c|}{} & \multicolumn{2}{c|}{ Dificultades vinculadas a condiciones externas } \\
\cline { 2 - 3 } & Situación socioeconómica familiar & Adaptación a la vida en la ciudad \\
\hline Mucho & $15(25.4 \%)$ & $1(1.7 \%)$ \\
\hline Bastante & $20(33.9 \%)$ & $11(18.6 \%)$ \\
\hline Algo & $14(23.7 \%)$ & $22(37.3 \%)$ \\
\hline Poco & $9(15.3 \%)$ & $23(39 \%)$ \\
\hline Nada & $1(1.7 \%)$ & $2(3.4 \%)$ \\
\hline
\end{tabular}




\section{Discusión}

Los resultados alcanzados hasta el momento en el marco de la investigación realizada permiten afirmar que uno de los principales desafíos para atender a las problemáticas del ingreso a las universidades públicas de Argentina es considerar al primer año como un ciclo con características específicas. En este sentido, los profesores de primer año de la universidad representan referentes claves en el proceso de afiliación de los estudiantes a la institución. Las condiciones en las que ejercen su trabajo requieren una revisión exhaustiva, atendiendo a la particularidad del primer año como así también a la necesidad de construir y profundizar espacios de articulación al interior del propio ciclo y con el nivel anterior.

Tanto en la fase cualitativa como cuantitativa de la investigación encontramos diferencias relativas al sistema de ingreso que los docentes consideran más apropiado. En la muestra analizada observamos que los docentes con mayor antigüedad y edad son quienes en mayor medida discutieron la modalidad de ingreso irrestricto. Sin embargo, en términos generales, la mayoría acuerda con el ingreso directo con instancias de ambientación que tiendan a acompañar a los ingresantes en los primeros tiempos de la vida universitaria.

Otro punto que cabe destacar es el gran porcentaje de docentes que otorgan centralidad a las problemáticas propias de los ingresantes como causas principales del abandono en primer año. Estas respuestas difieren de las tendencias actuales de investigación sobre dicha problemática, las cuales sostienen la necesidad de superar enfoques centrados en los estudiantes como sujetos responsables de sus propios fracasos, para atender a los condicionantes políticos e institucionales. Ahora bien, un aspecto que sí destacan es la notable influencia de la desaprobación recurrente de las evaluaciones como causa del abandono. En este sentido, cabe señalar que el tipo de exámenes que se diseñan requieren una especial atención en primer año, por el impacto de sus resultados como elemento definitorio nada menos que en la continuidad o no de las trayectorias estudiantiles.

Teniendo en cuenta que el primer ciclo es el que presenta mayor complejidad, en tanto es allí donde se producen los índices más altos de abandono, apuntamos hacia una revisión de éste en materia académica, curricular y pedagógica. Dicha revisión ameritaría una reflexión integral sobre el conjunto de factores estructurales y cualitativos que inciden en la enseñanza en primer año: condiciones de trabajo docente, infraestructura, tipos de cargos, diseño de programas de estudios, definición de los contenidos y formas de transmisión, modos que asume la evaluación. Además de focalizar en cada una de estas cuestiones, futuros estudios podrían explorar en mayor profundidad y con mayor extensión diferencias de acuerdo con las facultades y áreas de conocimiento de origen de los sujetos consultados. 


\section{Referencias}

Aponte-Hernández, Eduardo (2008), "Desigualdad, inclusión y equidad en la Educación Superior en América Latina y el Caribe: tendencias y escenario alternativo en el horizonte 2021", en Conferencia Regional de Educación superior: Tendencias de la educación superior en América Latina y el Caribe, Cartagena de Indias, Colombia, <http://www.cres2008.org/es/info_documentos. php> [Consulta: marzo de 2019].

Blanco, Rafael (2014), Universidad intima y sexualidades públicas. La gestión de la identidad en la experiencia estudiantil, Buenos Aires, Miño y Dávila.

Borgobello, Ana y Nadia Peralta (2011), "Funciones tutoriales y auxiliares de la docencia en Argentina", Revista Mexicana de orientación Educativa, vol. VIII, núm. 20, pp. 48-55.

Canales, Francisca, Eva Alvarado y Elia Pineda (1994), Metodología de la investigación. Manual para el desarrollo de personal de salud, Washington, OPS.

Coomber, Ross (1997), "Using the internet for survey research", Sociological Research Online, núm. 2, pp. 1-18, <https://journals.sagepub.com/doi/10.5153/sro.73> [Consulta: noviembre de 2018].

Carli, Sandra (2012), El estudiante universitario. Hacia una historia del presente de la educación pública, Buenos Aires, Siglo Veintiuno.

Carli, Sandra (2014), "Algunos aportes para pensar los primeros años de la formación universitaria desde la perspectiva de los estudiantes", Política Universitaria, 1, Buenos Aires, IEC-CONADU, pp. 15-19.

Carli, Sandra (2016), "Deconstruir la profesión académica: tendencias globales y figuras históricas. Una exploración de las biografías académicas de profesoras universitarias", Propuesta Educativa, núm. 45, pp. 81-90.

Chiroleu, Adriana (1999), El ingreso a la universidad: las experiencias de Argentina y Brasil, Rosario, UNR Editora.

Chiroleu, Adriana (2009), "La inclusión en la educación superior como tema de la agenda de gobierno en América Latina. Una reflexión sobre las propuestas del CRES/2008”, Universidades, vol. LIX, núm. 40, pp. 19-28.
Coulon, Alain (2008), A condição de estudante. A entrada na vida na universitaria, Salvador, EDUFBA.

Decreto 1246 (2015), Convenio colectivo para docentes de universidades nacionales, Argentina, <http://dga.unsa. edu.ar/images/patrimonio/normas/decreto_1246. pdf $>$ [Consulta: diciembre de 2017].

De Garay, Adrián (2001), Los actores desconocidos. Una aproximación al conocimiento de los estudiantes, México, ANUIES.

Díaz de Rada, Vidal (2012), "Ventajas e inconvenientes de la encuesta por Internet", Papers, vol. 97, núm. 1, pp. 193-223.

Edelstein, Gloria (2014), "Una interpelación necesaria. Enseñanza y condiciones de trabajo en la universidad", Política Universitaria, núm. 1, pp. 20-25.

Ezcurra, Ana María (2011), Igualdad en educación superior. Un desafio mundial, Buenos Aires, UNGS.

Fachelli, Sandra y Pedro López-Roldán (2017), "Análisis del sistema universitario argentino. Una propuesta inicial de indicadores", Dipòsit Digital de Documentos Universitat Autònoma de Barcelona, < https://ddd.uab.cat/ pub/estudis/2017/171528/Indicadores_del_sistema_ universitario_argentino.pdf $>$ [Consulta: febrero de 2018].

Feldman, Daniel (2015), "Para definir el contenido. Notas y variaciones sobre el tema en la universidad", Trayectorias universitarias, núm.1, pp. 20-27, <http:// www.revistas.unlp.edu.ar/TrayectoriasUniversitarias/ article/view/2309/2254> [Consulta: marzo de 2018].

Fernández Lamarra, Norberto y Cristian Pérez Centeno (2011), "La profesión académica universitaria en América Latina, en perspectiva comparada", Educaçao, vol. 36, núm. 3, pp. 351-363.

Figuera, Pilar y Manuel Álvarez (2014), "La intervención orientadora y tutorial en la adaptación y persistencia del alumnado en la universidad", Revista de Orientación Educacional, vol. 28, núm. 54, pp. 31-49.

Gallart, María Antonia (1992), "La integración de métodos y la metodología cualitativa. Una reflexión 
desde la práctica de la investigación", en Floreal Forni, Ma. Antonia Gallart e Irene Vasilachis, Métodos cualitativos II. La práctica de la investigación, Buenos Aires, Centro Editor de América Latina, pp. 107-152.

García de Fanelli, Ana María (2015), "La cuestión de la graduación en las universidadesn nacionales de la Argentina: Indicadores y políticas públicas a comienzos del siglo XXI", Propuesta Educativa, núm. 43, pp. 17-31.

García de Fanelli, Ana María y Marina Moguillansky (2009), "La estructura de incentivos según la percepción de los docentes universitarios", en A. García de Fanelli (ed.), Profesión académica en la Argentina: Carrera e incentivos a los docentes en las Universidades Nacionales, Buenos Aires, CEDES, pp. 108-133.

Gluz, Nora (ed.) (2011), Admisión a la universidad y selectividad social. Cuando la democratización es más que un problema de "ingresos", Los Polvorines, UNGS.

Guzmán, Carlota (2013), Los estudiantes y la universidad. Integración, experiencias e identidades, México, ANUIES.

Hernández-Sampieri, Roberto, Carlos FernándezCollado y Pilar Baptista Lucio (2008), Metodología de la investigación, México, McGrawHill.

IEG-CONADU (2014), "Programa de fortalecimiento de la docencia en los primeros años de las carreras universitarias", Política Universitaria, núm. 1, pp. 2-7.

IESALC-UNESCO (2008), Conferencia Regional de Educación Superior en América Latina y El Caribe. Declaración Final, <http://www.oei.es/historico/salactsi/cres.htm> [Consulta: enero de 2018].

Johnston, Bill (2013), El primer año de universidad. Una experiencia positiva de transición, Madrid, Narcea.

Juarros, Fernanda, Silvia Llomovate e Inés Cappellacci (2016), "Los docentes universitarios en Argentina. Sus condiciones de trabajo en la actualidad", XI Seminario Internacional de la Red Estrado, < http://redeestrado. org/xi_seminario/pdfs/eixo7/347.pdf> [Consulta: marzo de 2019].

Krotsch, Pedro (2002), "Los universitarios como actores de reformas en América Latina: ¿han muerto los movimientos estudiantiles?", Espacios en blanco, núm.12, pp. 19-50.

Mancovsky, Viviana (2015), "Algumas reflexoes sobre os jovens que chegam à universidade e os profesores que os recebem: o cuidado atravès do ensino", en G. Gonçalves Dos Santos, S. Rocha Sampaio e A. Carvalho (org), Observatório da vida estudantil. Avaliaçao e qualidade no ensino superior: Formar como e para que mundo?, Salvador, EDUFBA, pp. 299-313.

Michavila Pitarch, Francisco (2015), "La acogida de los nuevos estudiantes", Revista de docencia universitaria, vol. 13, núm. 2, pp. 37-51.

Ministerio de educación de la Nación Argentina (2017), Sintesis de información estadisticas universitarias 2016-2017, <https://www.argentina.gob.ar/sites/default/files/ sintesis_2016-2017.pdf> [Consulta: marzo de 2019].

Moscoloni, Nora (2005), Las nubes de datos. Métodos para analizar la complejidad, Rosario, UNR Editora.

Ortega, Facundo (2008), Atajos. Saberes escolares y estrategias de evasión, Buenos Aires, Miño y Dávila.

Oviedo, Gilberto (2004), "La definición del concepto de percepción en psicología con base en la Teoría Gestalt", Revista de Estudios Sociales, núm. 18, pp. 89-96.

Pierella, María Paula (2014), La autoridad en la universidad. Vinculos y experiencias entre estudiantes, profesores y saberes, Buenos Aires, Paidós.

Pierella, María Paula (2018), "El primer año de universidad desde la perspectiva de los profesores. Políticas de recepción, enseñanza y curriculum", Revista Espacios en blanco, núm. 28, pp. 161-181.

Pozzo, María Isabel, Ana Borgobello Ana y María Paula Pierella (2018), "Uso de cuestionarios en investigaciones sobre universidad: Análisis de experiencias desde una perspectiva situada", Revista Latinoamericana de Metodología de las Ciencias Sociales, vol. 8, núm. 2, <https://www.relmecs.fahce.unlp.edu.ar/article/ view/Relmecse046> [Consulta: enero de 2019].

Rinesi, Eduardo (2015), Filosofia (y) política de la universidad, Buenos Aires, IEG-UNGS. 
Secretaría de Planeamiento, Dirección General de Estadística Universitaria, Universidad Nacional de Rosario (2018), Boletín Estadístico, núm. 69, <https:// www.unr.edu.ar/noticia/1387/boletines-estadisticos> [Consulta: diciembre de 2018].

Sigal, Víctor (1993), "El acceso a la educación superior. El ingreso irrestricto: ¿una falacia?”, Desarrollo económico, vol. 33, núm. 130, pp. 265-280.

Silva Laya, Marisol (2011), "El primer año universitario. Un tramo crítico para el éxito académico", Perfiles Educativos, núm. 120, pp. 7-32.

Socolovsky, Yamile (2014), "Editorial", Política Universitaria, núm.1, p. 1.
Suasnábar, Claudio y Laura Rovelli (2016), "Ampliaciones y desigualdades en el acceso y egreso de estudiantes a la Educación Superior en la Argentina", Pro.posições, vol. 27, núm. 3, pp. 81-104.

Tinto, Vincent (1993), "Reflexiones sobre el abandono de los estudios superiores", Perfiles Educativos, núm. 62, pp. 56-63.

Yorke, Mantz y Bernard Longden (2007), The first-year experience in highereducation in the UK, Final Report for the Higher Education Academy, <www.heacademy.ac.uk/assets/ documents/research/fye/firstyearexperiencerevised. pdf.> [Consulta: noviembre de 2017].

\section{Cómo citar este artículo:}

Pierella, María-Paula, Nadia-Soledad Peralta y María-Isabel Pozzo (2020), "El primer año de la universidad. Condiciones de trabajo docente, modalidades de admisión y abandono estudiantil desde la perspectiva de los profesores", Revista Iberoamericana de Educación Superior (RIES), vol. XI, núm. 31, pp. 68-84, DOI: https://doi.org/10.22201/iisue.20072872e.2020.31.706 [Consulta: fecha de última consulta]. 